\title{
Conciliação: sinônimo de acesso qualitativo à justiça em tempo razoável
}

\author{
Conciliation: synonym of qualitative access to justice \\ at reasonable time
}

\author{
Elias Pereira de Sousa ${ }^{\mathrm{I}}$ \\ IUniversidade do Tocantins, UNITINS, Brasil \\ Flavia Afini Bovo ${ }^{I}$ \\ ÂNGEla IsSA HaONAT ${ }^{\mathrm{I}}$ \\ TARSIS BARRETO OLIVEIRA ${ }^{\mathrm{I}}$
}

Resumo A atividade desempenhada pelo Poder Judiciário constitui-se como uma das balizas garantidoras dos princípios de um Estado Democrático de Direito, cabendo ao Estado-Juiz a responsabilidade perante a sociedade de dirimir conflitos. No Brasil, são constitucionalmente assegurados aos cidadãos o direito fundamental de acesso à justiça, bem como, a garantia da razoável duração do processo. O crescente número de ações em trâmite perante a justiça brasileira e uma série de fatores de ordem estrutural e cultural têm conduzido a uma crise da jurisdição em âmbito nacional, a qual tem impedido a concretização de um acesso à justiça de qualidade em tempo satisfatório. Tal crise tem gerado a necessidade de reflexão acerca da forma usual de composição de litígios e ainda a inserção no ordenamento jurídico pátrio de meios adequados de resolução de conflitos como perspectiva de concretização do papel da função jurisdicional nos moldes constitucionalmente estabelecidos. Nesse contexto, o instituto da conciliação surge no cenário nacional como instrumento adequado de solução de conflitos e perspectiva de concretização de acesso qualitativo à justiça em tempo razoável.

Palavras-chave: Crise. Acesso À Justiça. Duração RazoÁvel do ProCEsso. Conciliação. 
Abstract The activity carried out by the Judiciary is one of the beacons guaranteeing the principles of a Democratic State of Law, and the State-judge is responsible to the society to resolve conflicts. In Brazil, citizens are constitutionally guaranteed the fundamental right of access to justice, as well, as ensuring the reasonable duration of the process. The growing number of lawsuits before the Brazilian courts, coupled with a number of structural and cultural factors, has led to a crisis of jurisdiction at the national level, which has prevented the achievement of access to quality justice in satisfactory time. Such a crisis has generated the need for reflection on the usual form of litigation composition, as well as the insertion in the legal order of the country of adequate means of conflict resolution as a perspective of concretizing the role of the jurisdictional function in a constitutionally established manner. In this context, the conciliation institute appears on the national scene as an adequate instrument of conflict resolution and perspective of achieving qualitative access to justice in a reasonable time.

Key-words: Crisis. Access to Justice. Reasonable Duration of the Process. Conciliation.

\section{INTRODUÇÃO}

O Poder Judiciário brasileiro há décadas encontra-se mergulhado numa crise profunda e tem perdido ao longo dos anos sua capacidade de regular e solucionar conflitos de forma efetiva e no tempo adequado.

A Constituição Federal de 1988, em seu artigo $5^{\circ}$., XXXV, elencou o acesso à justiça como direito fundamental, sendo que, em 2004, pela Emenda Constitucional $n^{\circ}$. 45, foi ainda incluída no texto constitucional a garantia da razoável duração do processo (art. $5^{\circ}$., LXXVIII), tendo sido tais dispositivos, em conjunto, apresentados ao cidadão pátrio como perspectiva de acesso a uma justiça efetiva, o que pressupõe, para tanto, um serviço judiciário de qualidade e que seja prestado em tempo adequado.

Nessa conjuntura, nos últimos anos, os métodos tradicionais de solução de conflitos, isoladamente, não têm demonstrado aptidão no sentido de dar concretude à promessa constitucional, tendo surgido os 
denominados métodos adequados de solução de conflitos (conciliação, mediação e arbitragem) como instrumentos capazes de materialização do estabelecido na Carta Magna, os quais, especialmente a partir da edição da Resolução no ${ }^{\circ} 125$ do Conselho Nacional de Justiça, de 29 de novembro de 2010, que dispõe sobre a Política Judiciária Nacional de tratamento adequado dos conflitos de interesses no âmbito do Poder Judiciário, despontaram no cenário nacional como perspectiva de concretização de uma justiça dotada de efetividade.

Entre os métodos adequados de solução de conflitos capazes de propiciar ao cidadão brasileiro uma justiça de qualidade ofertada em tempo razoável, tem recebido especial destaque a conciliação, isso em razão do novo Código de Processo Civil (Lei nº 13.105, de 2015), que estabelece em seu artigo 334 a realização de audiência conciliatória como fase obrigatória do procedimento cível.

O presente estudo tem como foco a análise do instituto da conciliação como método adequado de resolução de conflitos apto a se desenvolver como sinônimo de acesso qualitativo à justiça em tempo razoável.

\section{A CRISE DA JUSTIÇA BRASILEIRA}

O sistema de justiça brasileiro aparenta ter sido concebido para não funcionar, uma vez que tem se demonstrado extremamente desprovido de eficiência. É impossível fugir ao fato de que a justiça brasileira, quando funciona, o faz de forma precária e deficiente, raramente conseguindo aliar celeridade e qualidade (NALINI, 2011, p. 127).

Tramitam atualmente no Brasil mais de 79 milhões de processos, conforme dados do Relatório Justiça em Números 2017, disponíveis no site do Conselho Nacional de Justiça; sendo que, segundo dados do IBGE (2017, on-line) referentes à estimativa da população brasileira, o Brasil, em julho de 2016, alcançaria o número de 206.081.432 habitantes, ou seja, tais dados, analisados conjuntamente, indicam que para cada 2,5 brasileiros, há um processo em tramitação.

$\mathrm{O}$ excesso de demandas judiciais ajuizadas, como consequência de fatos sociais, políticos e econômicos é um dos fatores que têm impedido que a justiça brasileira ofereça à população uma prestação ju- 
risdicional de qualidade num espaço de tempo razoável (CARBONAR, 2013, p. 94).

Aliada a esse fator, associa-se, ainda, a cultura da litigiosidade, a qual se encontra arraigada no meio social brasileiro e faz que litígios, muitas vezes de baixa complexidade, cheguem até o mais alto nível da Justiça brasileira, qual seja, o Supremo Tribunal Federal, para apreciação.

Vários são os óbices que têm se apresentado como impeditivos do exercício da atividade jurisdicional de forma plena, como a morosidade no julgamento dos processos, cuja tramitação se arrasta, muitas vezes, por anos a fio; a dificuldade de efetivação das decisões judiciais, o que gera um descrédito em relação à justiça; o excesso de recursos existentes, os quais são utilizados como meios procrastinatórios; a falta de gestão e de uniformização dos procedimentos; o desrespeito às normativas de ordem constitucional; a falta de infraestrutura, bem como, de desenvolvimento de tecnologias capazes de otimizar e aperfeiçoar os serviços cartorários e judiciais; a inexistência de defensorias públicas organizadas e com capacidade de atendimento proporcional à demanda da população hipossuficiente; a visão retrógrada dos operadores do Direito que resistem às mudanças, e também, a falta de comprometimento de tais profissionais em adotarem uma postura humanística e ética (CAMARGO, 2010, p. 61).

Assim, tais óbices polarizam a crise do sistema judiciário, apresentando-se como obstáculo à concretização do direito fundamental de acesso à justiça constitucionalmente garantido, especialmente quando se parte da premissa de que o efetivo acesso à justiça não possui o mesmo significado de simples acesso quantitativo ao Poder Judiciário; ao contrário, somente se pode considerar o direito fundamental de acesso à justiça concretizado em sua plenitude, caso este se traduza ao cidadão como acesso à justiça revestido de um alcance de ordem eminentemente qualitativa.

\section{Acesso Qualitativo À JUSTiÇa}

A Constituição Federal de 1988 estabeleceu o acesso à justiça como um direito fundamental, conforme se infere do texto do artigo 
$5^{\circ}$., inciso XXXV, que dispõe que "a lei não excluirá da apreciação do Poder Judiciário lesão ou ameaça a direito".

Em um sistema jurídico moderno e ancorado em critérios igualitários, o acesso à justiça é concebido como premissa essencial e indispensável à construção de um sistema que tenha como fundamento não apenas a proclamação de direitos, mas também que vise à efetiva garantia e concretização de tais direitos, constituindo-se, sob esse enfoque, no mais básico dos direitos humanos (CAPPELLETTI; GARTH, 1988, p. 12).

É certo que a redemocratização do Brasil, que levou à promulgação do texto constitucional, de 1988, induziu a uma maior credibilidade da sociedade na possibilidade de utilização da via judicial para o alcance de direitos (SANTOS, 2011, p. 14), tendo o acesso à justiça deixado o campo da teoria para reverberar na redação constitucional e para se transmudar numa tentativa, por parte de todos os operadores do Direito inseridos no sistema judicial brasileiro, de abertura e ampliação dos caminhos condutores à justiça a todos os cidadãos, especialmente aos menos favorecidos (NALINI, 2000, p. 20).

Nesse aspecto, tem tomado dimensão a percepção de que o alargamento da porta da Justiça brasileira, refletido no texto da Constituição, somente logrou prosperar sob o ponto de vista quantitativo, ou seja, sob o aspecto do direito de ingresso em juízo, não tendo ainda se concretizado com maior amplitude sob o ângulo qualitativo, o qual se encontra ligado ao aspecto material.

Isso porque o acesso à justiça qualitativa representa não somente o acesso aos tribunais, mas sim se traduz na solução do litígio existente entre as partes de forma legítima, ou seja, com a prestação de uma adequada tutela jurisdicional, lastreada em dar concretude aos direitos fundamentais, tendo como base os princípios constitucionais democráticos. Nesse mister, suscita Bezerra (2008, p. 250) a necessária mudança de postura de todos os operadores do Direito, bem como, dos demais atores sociais na criação de mecanismos para a busca de soluções rápidas e eficientes para os conflitos, seja nas vias judicial ou extrajudicial.

Nessa esteira de raciocínio, tem-se que, quanto ao direito fundamental de acesso à justiça, o principal objetivo do Estado não deve 
estar direcionado a assegurar aos cidadãos apenas o acesso formal aos tribunais, mas precisa estar voltado a fornecer à sociedade civil uma distribuição da justiça calcada numa ordem jurídica justa (CASTRO JÚNIOR, 1998, p. 132).

$\mathrm{O}$ acesso à justiça não significa, assim, o mero direito formal de propor ou contestar uma ação, devendo, ao contrário, consubstanciar-se no acesso a uma ordem jurídica justa, balizada pelo devido processo legal (MEDINA, 2010, p. 11).

Ao longo dos anos, o conceito de acesso à justiça sofreu importante transformação; lamentável, pois, o fato de que exista uma gama de autores que ainda conservam a aposta em um conceito de acesso à justiça de parâmetro quantitativo, ou seja, no qual a solução para a crise do sistema judicial está lastreada e possui como foco apenas aspectos quantitativos, cujos objetivos são o cumprimento e a superação de metas numéricas que redundem em números positivos estatisticamente (PEDRON, 2017, [s.p.]).

De outro modo, é fato que o acesso a uma justiça exclusivamente qualitativa totalmente dissociada do aspecto quantitativo não será capaz de atender aos anseios dos jurisdicionados, devendo, assim, buscar-se uma justiça predominantemente qualitativa, mas que também esteja conectada a parâmetros de ordem quantitativa, os quais têm como foco o fator da eficiência, a fim de que uma ordem jurídica justa chegue ao jurisdicionado em tempo adequado.

O Poder Judiciário, assim, embora tenha obtido avanços no que tange ao seu reconhecimento pela sociedade, muito pouco tem prosperado quanto à redução da morosidade judicial, ficando tal problemática visível quando se consideram os números disponibilizados pelos tribunais de justiça, bem como, pelo Conselho Nacional de Justiça, os quais denotam a falta de agilidade do Judiciário brasileiro, tendo como parâmetros os índices de congestionamento, o grau de recorribilidade, entre outros indicadores (FALCÃO, 2009, p. 28).

Nessa ótica, a taxa de congestionamento é um dos indicadores que mais clarificam a falta de agilidade do Poder Judiciário brasileiro, tendo se mantido em altos patamares, os quais ultrapassam os $70 \%$. Tal taxa 
constitui-se num indicador que mede o percentual de casos que permaneceram pendentes de solução ao final do ano-base, em relação ao número de processos que tramitaram (soma dos processos pendentes e dos baixados). Conforme se infere do Relatório Justiça em Números 2017 (2017, on-line), divulgado pelo Conselho Nacional de Justiça, a taxa bruta média de congestionamento, considerando-se o ano-base de 2016, alcançou os índices de 75,3\% na Justiça Estadual, 56,2\% na Justiça do Trabalho e 74,6\% na Justiça Federal, o que demonstra a ineficiência de o Poder Judiciário dar vazão aos casos que lhe são submetidos.

\section{A razoável duração do Processo}

Somente recentemente o direito de acesso à justiça num prazo razoável foi reconhecido como um prolongamento inerente e inseparável do direito de acesso à justiça, muito embora instrumentos jurídicos que datam do século XIII já fizessem menção à necessidade de agilidade processual, havendo registros até mesmo de que os súditos do rei João, desde o advento da Magna Carta, de 1215, já reivindicavam por uma justiça desprovida de atrasos e custas (ANNONI, 2008, p. 175).

A morosidade do Judiciário, para Falcão (2009, p. 28), é um "problema histórico e extremamente complexo". A falta de celeridade da justiça é assim uma dificuldade que vem sendo enfrentada pela sociedade há longo tempo, não sendo uma novidade do mundo moderno, tendo, todavia, se tornado mais latente "[...] nas últimas décadas, nomeadamente como um dos efeitos colaterais da globalização econômica, da sociedade de massa, complexa e cada vez mais litigiosa" (MAGALHÃES, 2016, p. 117).

A morosidade num pronunciamento judicial gera descrédito da população em relação à justiça, visto que a demora na prolação de uma decisão judicial faz que o conflito existente entre as partes se protraia no tempo, potencializando-se e trazendo como consequência a ampliação dos efeitos negativos decorrentes do problema de fundo pendente de solução (MENDES, 2014, p. 90). 
No Brasil, a Emenda Constitucional $n^{\circ}$. 45, de 2004, acresceu o inciso LXXVIII ao artigo $5^{\circ}$. da Constituição Federal, de 1988, para estabelecer que "a todos são assegurados, no âmbito judicial e administrativo, a razoável duração do processo e os meios que garantam a celeridade de sua tramitação".

$\mathrm{O}$ acesso à justiça, previsto no artigo $5^{\circ}$., XXXV, da Constituição, já contém em si mesmo o pressuposto de um pronunciamento judicial em tempo adequado; o qual sempre foi infrutífero em razão da persistente ausência de celeridade no sistema judiciário; estando aí a gênese do estabelecimento da garantia da razoável duração do processo, a qual traz em si o risco de se tornar ineficaz, gerando desapontamento aos jurisdicionados, uma vez que a declaração de um direito, desacompanhado das medidas estruturantes garantidoras de sua efetividade, não possibilitará a sua concretização como garantia individual (SILVA, 2014, p. 435).

Assim, com o advento da Constituição promulgada em 1988, a qual trouxe em seu bojo viabilidade para a realização de transformações no sistema judiciário brasileiro, o Poder Judiciário poderá se converter em "[...] uma verdadeira intelligentsia no processo de transformação social, através da absorção de conflitos nos modernos padrões da vontade do legislador constituinte e das expectativas sociais" (ARAÚJO, 2004, p. 331).

A morosidade do Judiciário não será combatida e vencida apenas com a utilização de métodos tradicionais, de modelos de gestão que se constituam em mera repetição dos já adotados. Não basta somente o aumento na produtividade dos magistrados e um incremento na prolação de sentenças judiciais. É necessário que haja mudança comportamental, uma mudança que conduza a uma cultura de paz, uma transformação capaz de controlar a demanda patológica que assola o sistema judiciário brasileiro. Há premente necessidade de que seja colocada "em curso uma dinâmica de experimentação institucional. Sem tanto, estaremos sempre a buscar um Poder Judiciário aquém do Estado democrático de direito" (FALCÃO, 2008, p. 28-29).

A eficiência da estrutura judiciária brasileira encontra-se comprometida tanto sob o enfoque do acesso à justiça qualitativo, bem como 
quantitativo, o que tem feito ganhar força o que Cappelletti e Garth (1988, p. 71) denominam como a terceira onda no sentido de incrementar o acesso à justiça pátrio, a qual parece apontar para a superação do modelo tradicional de solução de conflitos empregado pelo Poder Judiciário, pois encoraja tanto alterações nas formas procedimentais, mudanças na estruturação dos tribunais, utilização de pessoal alheio aos quadros do Judiciário, bem como "[...] modificações no direito substantivo destinadas a evitar litígios ou facilitar sua solução e a utilização de mecanismos privados ou informais de solução de litígios". Enquadram-se nessa terceira onda os meios adequados para a solução de conflitos, entre os quais se destaca a conciliação, que se abre como uma perspectiva nova e eficaz técnica de gestão do processo.

\section{O InSTITUTO DA CONCILIAÇÃo}

No Brasil, o instituto da conciliação teve seu primeiro regramento no bojo da Constituição, de 1824, a qual estabelecia em seu artigo 161 que "sem se fazer constar, que se tem intentado o meio da reconciliação, não se começará Processo algum”, estatuindo, ainda, em seu artigo 162 que tal atribuição ficaria a cargo dos juízes de paz, os quais, segundo o estatuído no texto constitucional, seria um cidadão eleito pela comunidade (MENDES, 2014, p. 86-87).

Em 1994, ainda sob a égide do Código de Processo Civil, de 1973, houve a criação da audiência de conciliação, a qual posteriormente recebeu a designação de audiência preliminar, cuja dispensa somente poderia ocorrer em causas que versassem sobre direitos indisponíveis. Tal implantação sofreu várias críticas, e pela Lei nº 10.444, de 2002, o artigo 331 do diploma processual civil pátrio passou a estabelecer que a audiência preliminar devesse ser designada nos casos em que a causa versasse sobre direitos que admitissem transação (GRECO, 2015, p. 90).

Paralelamente, em 1995, foi editada a Lei no .9 .099 , que dispõe sobre os Juizados Especiais Cíveis e Criminais e dá outras providências, tendo o instituto da conciliação recebido especial destaque, uma vez que o artigo 16 estabelece que "registrado o pedido, independentemente 
de distribuição e autuação, a Secretaria do Juizado designará a sessão de conciliação, a realizar-se no prazo de quinze dias".

No ano de 2010, o Conselho Nacional de Justiça, considerando a crescente valorização dos meios alternativos de solução de conflitos na doutrina brasileira atual, editou a Resolução $n^{0}$. 125, de 29 de novembro de 2010, pela qual instituiu uma Política Judiciária Nacional de tratamento dos conflitos de interesses, com o objetivo de assegurar a todos o direito à solução destes por meios adequados à sua natureza e peculiaridade, estipulando que cabe aos órgãos judiciários oferecer aos jurisdicionados mecanismos de solução de conflitos, especialmente os denominados meios consensuais (mediação e conciliação), devendo, ainda, ser disponibilizados aos jurisdicionados atendimento e orientação (DINAMARCO, 2016, p. 284-285); sendo objetivo central dessa Política Judiciária Nacional o acesso à justiça em seu espectro amplo, o qual, para a sua concretização, "exige não só efetividade, celeridade e adequação da tutela jurisdicional, mas uma atenção do Poder Judiciário a todos que tenham qualquer problema jurídico" (LUCHIARI, 2014, p. 7).

O Código de Processo Civil, de 2015, disciplina a audiência preliminar conciliatória em seu artigo 334 e parágrafos, passando essa a ter caráter obrigatório, excetuando-se apenas as hipóteses em que ambas as partes manifestarem de forma expressa o seu desinteresse na composição consensual ou nos casos em que não seja admitida a autocomposição.

O comparecimento à audiência de conciliação ou mediação na sistemática do Código de Processo Civil, de 2015, é um dever processual das partes, segundo Didier Jr. (2016, p. 625), sendo que o não comparecimento injustificado do autor ou do réu à audiência de conciliação é considerado ato atentatório à dignidade da justiça.

A conciliação, com o passar dos anos, seja em razão de instrumentos legislativos ou de adoção de políticas judiciárias, tem se fortalecido no ordenamento jurídico pátrio por ser considerada "[...] importante instrumento de consolidação da política de solução de litígios sem a intervenção estatal, através de seu poder de julgar” (RIBAS, 2014, p. 114) e vem se constituindo em verdadeira quebra de paradigma em relação 
aos meios tradicionais de solução de conflitos, especialmente considerando a celeridade que propicia na solução dos conflitos.

\section{A CONCILIAÇÃo COMO INSTRUMENTO DE ACESSO QUALITATIVO À JUSTIÇA EM UM PRAZO RAZOÁVEL}

Conforme consta do Relatório Justiça em Números 2017 (2017, on-line), divulgado pelo Conselho Nacional de Justiça, o tempo médio de duração de um processo, desde o seu protocolo, até a prolação de uma sentença de mérito na fase de conhecimento, considerando-se o ano-base de 2016, alcançou os seguintes índices quando considerados os dados referentes ao $1^{\circ}$. grau de jurisdição: 3 anos e 2 meses na Justiça Estadual; 1 ano na Justiça do Trabalho; e 4 anos e 2 meses na Justiça Federal.

Os dados mencionados indicam que o Poder Judiciário, utilizando os métodos tradicionais de solução de conflitos, encontra-se distante de conseguir distribuir justiça em tempo razoável. De outro modo, interessante observar que, embora seja corrente a afirmativa de que a conciliação possui o condão de reduzir o tempo de duração do processo judicial, quanto a tal aspecto, o Conselho Nacional de Justiça ainda não dispõe em seus relatórios de dados indicadores referentes a esse tempo.

Alguns tribunais, entretanto, têm adotado medidas na tentativa de se aferir o real impacto da conciliação na redução da morosidade processual. É o caso do Tribunal de Justiça do Distrito Federal e dos Territórios (TJDFT), que instituiu a Pesquisa de Satisfação do Usuário (PSU), a qual se constitui num instrumento de avaliação dos serviços prestados pelos Centros Judiciários de Solução de Conflitos (CEJUSCs). Conforme se infere do Relatório Anual 2016 (2017, on-line) referente ao Núcleo Permanente de Mediação e Conciliação (NUPEMEC), do Tribunal de Justiça do Distrito Federal e dos Territórios, segundo estimativa dos advogados ouvidos por meio da Pesquisa de Satisfação do Usuário, nos processos submetidos à conciliação nos CEJUSCS pertencentes a esse Tribunal, a redução do tempo médio de duração do processo atingiu os seguintes índices: em 54,4\% dos casos houve redução de até 1 ano; em 32,5\% a redução foi de 1 a 2 anos; em $8,7 \%$ o decréscimo do tempo na duração do processo atingiu de 3 a 4 
anos; em 2,3\% dos feitos alcançou-se uma diminuição de 5 a 6 anos; em $0,1 \%$ das causas mais de 6 anos; e em 1,9\% dos processos o prazo foi outro distinto das hipóteses preestabelecidas para a avaliação.

Embora os dados obtidos pelo Tribunal de Justiça do Distrito Federal e dos Territórios, por meio da Pesquisa de Satisfação do Usuário, ainda sejam incipientes e não indiquem uma situação em âmbito nacional, infere-se da análise destes que estão a indicar que a conciliação se constitui num instrumento apto a reduzir o tempo de duração do processo. Sob essa perspectiva, tem-se que a conciliação, para se afigurar como instrumento efetivo de acesso qualitativo à justiça, não pode se dissociar da razoável duração do processo, pois o tempo "é elemento imprescindível ao processo, é o que lhe confere dinâmica e movimento" (ANNONI, 2008, p. 193).

De outra banda, para que os seus objetivos sejam concretizados, a conciliação não pode nem deve ser concebida e direcionada para a solução da crise de morosidade do Judiciário, ou seja, não deve ser utilizada apenas como forma de se reduzir estoque processual; ao contrário, a conciliação precisa sim se constituir como maneira de solucionar de forma mais adequada os conflitos de interesses existentes no meio social, e a redução do número de processos deve ser apenas consequência do sucesso de sua aplicação, mas não sua finalidade originária (WATANABE, 2014, p. 3).

O procedimento conciliatório, como forma de acesso a uma justiça qualitativa, deve se traduzir, assim, em meio de se realizar justiça de modo célere e que leve em conta a concreta situação das partes envolvidas no processo, com o desiderato de que a efetividade pretendida no processo seja genuína (RIBAS, 2014, p. 215). Tudo isso, levando-se em consideração que a ideia de que o verdadeiro acesso à justiça tem a abrangência não apenas de prevenção e reparação de direitos, mas também de "[...] realização de soluções negociadas e o fomento da mobilização da sociedade para que possa participar ativamente dos procedimentos de resolução de disputas como de seus resultados" (FAVRETO, 2009, p. 13). 
Há de se ter preocupação com a real solução do processo, mas não nos moldes que têm sido observados em práticas desenvolvidas por determinados agentes do Poder Judiciário, os quais se utilizam da conciliação para alcançar fins numérico-estatísticos, lastreados em critérios apenas quantitativos, buscando desvencilhar-se do maior número de processos para o atingimento de metas e redução do número de processos em tramitação. É imprescindível que a conciliação seja direcionada a uma efetiva solução do problema de fundo existente entre as partes (NORONHA, 2013, p. 75).

Na visão de Cappelletti e Garth:

É significativo que um processo dirigido para a conciliação - ao contrário do processo judicial, que geralmente declara uma parte "vencedora" e outra "vencida" - ofereça a possibilidade de que as causas mais profundas de um litígio sejam examinadas e restaurado um relacionamento complexo e prolongado (CAPPELLETTI; GARTH, 1988, p. 84).

E para que haja equilíbrio entre os pilares de acesso qualitativo à justiça, aliado a uma razoável duração do processo, há de se atentar para a necessidade premente de mudança de comportamento e cultura, no sentido de que haja preocupação com a utilização da conciliação como forma efetiva de solução do conflito de fundo existente entre as partes, ou seja, o procedimento conciliatório há de alcançar a pacificação do conflito, a paz social, não devendo ser utilizado apenas como mecanismo de redução do número de processos em tramitação.

\section{ConsideraÇões FinAis}

O Poder Judiciário brasileiro há várias décadas encontra-se imerso numa crise numérica decorrente de vários fatores, tanto de ordem social, política, institucional, bem como, cultural.

A ineficiência do sistema judiciário pátrio, em seu modelo tradicional de solução de conflitos, tem sido óbice intransponível à concre- 
tização dos comandos constitucionais insculpidos nos incisos XXXV e LXXVIII do artigo $5^{\circ}$. da Constituição Federal, os quais disciplinam acerca do acesso à justiça e da razoável duração do processo, especialmente considerando que o acesso à justiça inserido no texto constitucional há de ser interpretado segundo os parâmetros de acesso à justiça qualitativo, ou seja, capaz de efetivamente garantir o direito da parte, entregando-lhe uma tutela jurisdicional adequada, e não apenas lhe garantindo o acesso aos tribunais.

Os métodos adequados de solução de conflitos, em especial a conciliação, têm surgido nesse cenário como possibilidade de uma real concretização de acesso à justiça qualitativo em tempo razoável, tendo se fortalecido especialmente após a instituição de uma Política Judiciária de Tratamento dos Conflitos de Interesses pela Resolução $n^{\circ} .125$ do Conselho Nacional de Justiça, bem como, pela entrada em vigor do Código de Processo Civil que disciplinou em seu artigo 334 a audiência de conciliação como fase do procedimento comum.

A conciliação, como meio alternativo de solução de conflitos, somente afigura-se como instrumento efetivo de acesso qualitativo à justiça quando se encontra alinhada ao conceito da razoável duração do processo; não devendo, todavia, tal alinhamento adquirir, na prática, o significado de utilização de tal instituto, em razão do caráter de celeridade que lhe é peculiar, apenas como mecanismo capaz de reduzir a crise numérica do Poder Judiciário, sem que haja preocupação com o emprego de tal instrumento como potencial elemento de transformação de uma cultura da litigiosidade numa cultura de paz, por meio da efetiva solução do conflito existente entre as partes.

\section{REFERÊNCIAS}

ANNONI, D. O direito humano de acesso à justiça no Brasil. Porto Alegre: Sérgio Antônio Fabris Editor, 2008.

ARAÚJO, R. C. de O Estado e o poder judiciário no Brasil, 2. ed. Rio de Janeiro: Editora Lumen Juris, 2004. 
BEZERRA, P. C. S. Acesso à justiça: um problema ético-social no plano da realização do direito, 2. ed. Rio de Janeiro: Renovar, 2008.

BRASIL. IBGE. Projeções e estimativas da população do Brasil e das Unidades da Federação. Disponível em: http:/www.ibge.gov.br/apps/populacao/ projecao/notatecnica.html. Acessado em 21 de fevereiro de 2017.

CAMARGO, D. M. de Jurisdição crítica e direitos fundamentais, 2. ed. Porto Alegre: Núria Fabris Editora, 2010.

CAPPELLETTI, M.; GARTH, B. Acesso à justiça. Tradução de Ellen Gracie Northfleet. Porto Alegre: Fabris, 1988.

CARBONAR, D. O. F. O princípio da razoável duração do processo: noções sobre o acesso qualitativo e efetivo ao Judiciário. In: Wambier, Teresa Arruda Alvim (Coord.). Revista de processo, ano 38, vol. 224, outubro de 2013. São Paulo: Revista dos Tribunais.

CASTRO JÚNIOR, O. A. de A democratização do judiciário. Porto Alegre: Sérgio Antônio Fabris Editor, 1998.

CONSELHO NACIONAL DE JUSTIÇA. Justiça em números - 2017, Ano-base 2016. Disponível em: http://www.cnj.jus.br/files/conteudo/arquivo/201 7/09/904f097f215cf19a2838166729516b79.pdf. Acessado em 11 de setembro de 2017.

DIDIER JUNIOR, F. Curso de direito processual civil: introdução ao direito processual civil, parte geral e processo de conhecimento, 18. ed. Salvador: Jus Podivm, 2016.

DINAMARCO, C. R. Instituições de direito processual civil, vol. I, 8. ed. São Paulo: Malheiros, 2016.

FALCÃO, J. O judiciário segundo os brasileiros. In: GUERRA, Sérgio (Org.). Transformações do Estado e do direito, 1. ed. Rio de Janeiro: FGV Editora, 2009.

FAVRETO, R. P. In: Manual de mediação judicial. Brasília: Ministério da Justiça, 2009.

GRECO, L. Instituições de processo civil, vol. II, 3. ed. Rio de Janeiro: Forense, 2015. 
LUCHIARI, V. F. L. Capacitação de conciliadores e mediadores. In: ALVES, José Carlos Ferreira (Coord.). Estudos avançados de mediação e arbitragem. Rio de Janeiro: Elsevier, 2014.

MAGALHÃES, W. Judiciário e globalização. Curitiba: Editora Juruá, 2016.

MEDINA, P. R. de G. Direito processual constitucional, 4. ed. Rio de Janeiro: Editora Forense, 2010.

MENDES, M. L. R. de C. P. Mediação e Conciliação. Histórico dos Métodos Adequados de Solução de Conflitos e Experiências Contemporâneas no Brasil e em Outros Países. Das Técnicas de Conciliação e Mediação, suas Nuances, Pontos Convergentes e Aspectos Práticos. In: ALVES, José Carlos Ferreira (Coord.). Estudos avançados de mediação de arbitragem. Rio de Janeiro: Elsevier, 2014.

NALINI, J. R. Há esperança de justiça eficiente? In: MEZARROBA, Vladmir Oliveira da Silveira Orides (Coord.). Justiça e [o paradigma da] eficiência. São Paulo: Revista dos Tribunais, 2011.

O juiz e o acesso à justiça, 2. ed. São Paulo: Revista dos Tribunais, 2000.

NORONHA, J. O. N. A Contribuição da Reforma do CPC para Resolução de Conflitos. In: Associação dos magistrados do estado do Rio de Janeiro. Conciliação e mediação. Aspectos Jurídicos, Econômicos e Sociais, Rio de Janeiro, Memory - Centro de Memória Jurídica, 2013.

PEDRON, F. Q. Acesso à justiça qualitativo no estado democrático de direito. Revista Jus Navigandi, ISSN 1518-4862, Teresina, ano 18, n. 3.525, 24 fev. 2013. Disponível em: <https://jus.com.br/artigos/23802>. Acessado em 18 fevereiro de 2017.

RIBAS, C. Etapas da conciliação. In: ALVES, José Carlos Ferreira (Coord.). Estudos avançados de mediação de arbitragem. Rio de Janeiro: Elsevier, 2014.

SANTOS, B. de S. Para uma revolução democrática da justiça, 3. ed. São Paulo: Cortez Editora, 2011.

SILVA, J. A. da. Curso de direito constitucional positivo, 37. ed. São Paulo: Malheiros Editores LTDA, 2014.

TJDFT. Relatório Anual NUPEMEC 2016. Disponível em: http://www.tjdft.jus. br/institucional/2a-vice-presidencia/nupemec/relatorios-1/nupemec/relatorios/ 
Relatorio_Anual_NUPEMEC_2016.pdf, acessado em 11 de setembro de 2017.

WATANABE, K. A política nacional de tratamento adequado dos conflitos de interesses. In: ALVES, José Carlos Ferreira (Coord.). Estudos avançados de mediação e arbitragem. Rio de Janeiro: Elsevier, 2014.

Sobre os autores

\section{Elias Pereira de Sousa}

Mestrando em Prestação Jurisdicional e Direitos Humanos pela UFT/Esmat. Pós-Graduado em Educação, Comunicação e Tecnologias Contemporâneas. Graduado em Direito e Letras. Técnico Judiciário - atualmente como assessor jurídico na Vara de Violência Doméstica de Palmas TO - Tribunal de Justiça do Estado do Tocantins.

http://lattes.cnpq.br/6564952251457995

E-mail: elisdouglas@yahoo.com.br

\section{Flavia Afini Bovo}

Mestranda em Prestação Jurisdicional e Direitos Humanos pela UFT/ ESMAT. Pós-Graduada em Direito Constitucional. Juíza de Direito vinculada ao Tribunal de Justiça do Estado do Tocantins.

http://lattes.cnpq.br/2327771570724693

E-mail: flaviabovo@gmail.com.

ÂNGELA Issa HaOnat

Doutora em Direito Constitucional pela PUC/SP. Professora da Universidade Federal do Tocantins. Professora do Mestrado em Prestação Jurisdicional e Direitos Humanos da UFT/ESMAT. Advogada em Palmas/TO.

http://lattes.cnpq.br/9421403351506139

E-mail: ahaonat@gmail.com. 


\section{Tarsis Barreto Oliveira}

Doutor e Mestre em Direito pela UFBA. Professor Adjunto de Direito da Universidade Federal do Tocantins. Coordenador e Professor do Mestrado em Prestação Jurisdicional e Direitos Humanos da UFT/ESMAT. Autor de obras jurídicas.

http://lattes.cnpq.br/2822267824059777

E-mail: tarsisbarreto@uft.edu.br.

Submetido em: 17-4-2017

Aceito em: 11-7-2017 